\title{
Cost-Effectiveness Of Midostaurin In The Treatment Of Acute Myeloid Leukemia With The FLT3 Mutation In Spain
}

This article was published in the following Dove Press journal: ClinicoEconomics and Outcomes Research

\author{
Ainhoa Arenaza' \\ Raúl Diez iD ${ }^{2}$ \\ Jordi Esteve ${ }^{3}$ \\ Roberta Di Nicolantonio ${ }^{4}$ \\ Joana Gostkorzewicz ${ }^{4}$ \\ Carlos Martínez (iD) \\ Diana Martínez Llinàs 6 \\ Joaquin Martinez-Lopez (iD) ${ }^{7}$ \\ Pau Montesinos ${ }^{8}$ \\ Aída Moure-Fernández ${ }^{6}$ \\ Jorge Sierra ${ }^{9}$ \\ Joan Lluís Vinent ${ }^{10}$ \\ 'Pharmacy Department, Clínico San \\ Carlos Hospital, Madrid, Spain; \\ ${ }^{2}$ Pharmacy Department, University De \\ Getafe Hospital, Madrid, Spain; \\ ${ }^{3}$ Hematology Department, Clinic \\ Hospital, Barcelona, Spain; ${ }^{4}$ Health \\ Economics and Outcome Research, \\ Novartis Farmacéutica S.A., Madrid, \\ Spain; ${ }^{5}$ Pharmacy Department, University \\ Hospital Araba, Vitoria, Spain; ${ }^{6}$ Oblikue \\ Consulting, S.L., Barcelona, Spain; \\ ${ }^{7}$ Hematology Department, University \\ Hospital 12 de Octubre, CNIO, \\ Complutense University, Madrid, Spain; \\ ${ }^{8}$ Hematology Department, University \\ Hospital La Fe, Valencia, \& CIBERONC, \\ Instituto Carlos III, Madrid, Spain; \\ ${ }^{9}$ Hematology Department, University \\ Hospital Santa Creu i Sant Pau, \\ Barcelona, Spain; ${ }^{10}$ Pharmacy \\ Department, Sant Joan de Déu Hospital, \\ Barcelona, Spain
}

Correspondence: Diana Martínez Llinàs Oblikue Consulting, S.L. C/Comte

d'Urgell, 240, 2-D, Barcelona 08036, Spain

Tel +34 932521377

Fax +34937379984

Email diana.martinez@oblikue.com
Purpose: The addition of midostaurin to standard chemotherapy (cytarabine and daunorubicin) has shown significant improvements in the survival of patients with acute myeloid leukemia with the FLT3 mutation (FLT3-AML). The objective of this study was to determine whether this intervention would be cost-effective in Spain.

Methods: A partitioned survival model with five health states was developed (diagnosis and induction, complete remission, no complete remission, transplantation and death). A lifetime time horizon and the Spanish National Health System perspective were adopted. During the first three years, permanence in the different health states was determined according to the results of the RATIFY study. In successive years, the death rates of the Spanish population adjusted by a factor to reflect long-term disease-related mortality were used. Utilities were obtained from the literature. Pharmacological costs (first and second line) and the costs of other health resources (hospitalizations, visits and tests) were included. The robustness of the model was evaluated by deterministic and probabilistic sensitivity analyses.

Results: The addition of midostaurin resulted in 1.46 life years gained (LYG) and 1.23 quality-adjusted life years (QALY) gained and implied an additional cost of $€$ 47,955, resulting in an incremental cost-effectiveness ratio (ICER) of $€ 32,854 / \mathrm{LYG}$ and an incremental cost-utility ratio of $€ 38,985 / \mathrm{QALY}$. In the univariate sensitivity analysis, the threshold of $€ 50,000 /$ QALY was not exceeded in any case; taking into consideration potential discounts of $20-40 \%$ in the PVL of midostaurin the ICER would be below $€ 30,000 /$ QALY, a commonly accepted threshold in Spain. In the probabilistic analysis, when the threshold was $€ 50,000$ /QALY, midostaurin was cost-effective in $82.3 \%$ of simulations.

Conclusion: According to our modeling, midostaurin, in combination with standard chemotherapy, could be an efficient alternative for the treatment of FLT3-AML in Spain.

Keywords: AML, modeling, efficiency, health economics, economic evaluation

\section{Introduction}

Acute myeloid leukemia (AML) is a heterogeneous hematologic malignancy characterized by the clonal expansion of myeloid blasts in peripheral blood, bone marrow and/or other tissues. ${ }^{1}$ AML is the most frequent type of acute leukemia in adults (5-8 cases per year per 100,000 persons $)^{2}$ and leads to $4-6$ deaths annually per 100,000 persons. $^{3}$

Although the etiology of the disease is unknown, numerous cytogenetic and molecular abnormalities that have implications for the prognosis and treatment have been identified. These include mutations in the gene that encodes FMS-like tyrosine 
kinase 3 (FLT3), which occur in approximately one third of patients with AML (FLT3-AML) and result in a poor prognosis. $^{3}$

The therapeutic management of FLT3-AML depends fundamentally on the patient's physical state, which determines whether they can receive intensive chemotherapy, and the cytogenetic/molecular profile of the disease, which determines the prognosis and the risk of relapse. ${ }^{1,4}$

Candidate patients for intensive chemotherapy generally receive induction treatment with cytarabine and an anthracycline (daunorubicin or idarubicin), followed by consolidation strategies based on the use of high-dose cytarabine. $^{1}$

Chemotherapy may be followed by allogeneic hematopoietic stem cell transplantation (HSCT) when the patient has intermediate or high risk genetics and the benefit-risk balance is in favor of HSCT. ${ }^{1}$ In general, allogeneic HSCT is recommended in patients with an expected incidence of relapse of $>35-40 \%{ }^{1}$

Midostaurin is an inhibitor of multiple kinases, including FLT3. One indication for midostaurin is the treatment of adult patients with newly diagnosed FLT3-AML, in combination with standard induction (daunorubicin and cytarabine) and consolidation (high dose cytarabine) chemotherapy, followed by midostaurin monotherapy as maintenance treatment in patients who have achieved a complete response. ${ }^{5}$

In the RATIFY study, a randomized, double-blind, phase III clinical trial which included 717 patients, the addition of midostaurin to standard treatment provided significant reductions in the risk of death (hazard ratio $[\mathrm{HR}]=0.78 ; 95 \% \mathrm{CI}=0.63-0.96, \mathrm{p}=0.009)$ and events $(\mathrm{HR}=0.78,95 \% \mathrm{CI}=0.66-0.93, \mathrm{p}=0.002) .{ }^{6}$ The use of midostaurin also increased the rate of complete remission (CR) when all-reported CRs within 30 days after the end of treatment were considered $(68 \%$ vs $59 \%, \mathrm{P}=0.04){ }^{4}$

The objective of this study was to determine whether the addition of midostaurin to standard induction chemotherapy and consolidation with cytarabine and daunorubicin, followed by maintenance treatment with midostaurin monotherapy, would be a cost-effective intervention compared with standard chemotherapy induction and consolidation therapy in patients with FLT3-AML in Spain.

\section{Materials And Methods}

An economic evaluation was carried out, including costeffectiveness and cost-utility analyses, adopting the
Spanish National Health System perspective and considering only direct health costs.

To capture all the costs and benefits of the introduction of midostaurin in the treatment of FLT3-AML, a lifetime time horizon was adopted. A discount rate of 3\% per year was applied to costs and benefits, as recommended by national pharmacoeconomic guidelines when the time horizon of the analysis is $>1$ year. $^{7,8}$

The model is an adaptation of the model presented to NICE, ${ }^{9}$ and adaptations of this model were also submitted to $\mathrm{CADTH}^{10}$ and HAS. ${ }^{11}$ NICE recommendations on the economic evaluation of midostaurin ${ }^{9}$ and the opinion of a panel of Spanish clinical experts were taken into account when carrying out the analysis.

\section{Patients}

A population with the same clinical characteristics as the RATIFY study population was analyzed - adult patients with recently diagnosed FLT3-AML who were candidates for standard chemotherapy. In the RATIFY study, the mean age at diagnosis was 47.9 years and $55.5 \%$ of patients were female. The baseline characteristics of the patients included in the RATIFY study are described elsewhere $^{6}$ and are summarized in the supplementary material (Table S1).

\section{Therapy}

In the base case, the therapeutic alternatives considered in the RATIFY study were compared. ${ }^{6}$ Taking into account the study protocol, a maximum duration of 2 cycles was established for the induction phase, 4 cycles for the consolidation phase and 12 cycles for the maintenance phase. ${ }^{5,6}$ The proportion of patients achieving each treatment cycle within the RATIFY study is shown in Figure S2.

Additionally, it was considered that all patients who did not respond or relapsed after first-line treatment would receive salvage treatment. Based on the opinion of a panel of experts, it was considered that $75 \%$ of patients would receive a cycle of fludarabine, cytarabine and idarubicin (FLAG-IDA) and that the remaining $25 \%$ would receive a cycle of mitoxantrone, etoposide and cytarabine (MEC).

The regimens and doses of the therapies considered in each treatment phase are described in Table 1. For the induction, consolidation and maintenance treatments, the regimens, doses and durations of treatment observed in the RATIFY clinical trial ${ }^{6}$ were adopted. For the other treatments, the most frequent regimens and doses in clinical practice (validated by clinical experts) were adopted. 
Table I Regimens Considered In Each Treatment Phase

\begin{tabular}{|c|c|c|}
\hline Treatments & Active Principle & Regimen \\
\hline \multicolumn{3}{|l|}{ Ist line chemotherapy: intervention therapy } \\
\hline Induction (cytarabine + daunorubicin + midostaurin) & $\begin{array}{l}\text { Cytarabine } \\
\text { Daunorubicin } \\
\text { Midostaurin }\end{array}$ & $\begin{array}{l}200 \mathrm{mg} / \mathrm{m}^{2} / \text { day (days } \mathrm{I}-7 \text { ) } \\
60 \mathrm{mg} / \mathrm{m}^{2} / \text { day (days } \mathrm{I}-3 \text { ) } \\
50 \mathrm{mg} \text { twice a day (days } 8-2 \mathrm{I} \text { ) }\end{array}$ \\
\hline Consolidation (high dose cytarabine + midostaurin) & $\begin{array}{l}\text { High dose cytarabine } \\
\text { Midostaurin }\end{array}$ & $\begin{array}{l}\left.3,000 \mathrm{mg} / \mathrm{m}^{2} / \text { day twice a day (days } \mathrm{I}, 3,5\right) \\
50 \mathrm{mg} \text { twice a day (days } 8-2 \mathrm{I} \text { ) }\end{array}$ \\
\hline Maintenance (midostaurin) & Midostaurin & $50 \mathrm{mg}$ twice a day (days I-28) \\
\hline \multicolumn{3}{|l|}{ Ist line chemotherapy: Comparator treatment } \\
\hline $7+3$ (cytarabine + daunorubicin $)$ & $\begin{array}{l}\text { Cytarabine } \\
\text { Daunorubicin }\end{array}$ & $\begin{array}{l}200 \mathrm{mg} / \mathrm{m}^{2} / \text { day (days } \mathrm{I}-7 \text { ) } \\
60 \mathrm{mg} / \mathrm{m}^{2} / \text { day }(\text { days } \mathrm{I}-3 \text { ) }\end{array}$ \\
\hline High dose cytarabine & High dose cytarabine & $\begin{array}{l}3,000 \mathrm{mg} / \mathrm{m}^{2} / \text { day twice a day } \\
(\text { days } 1,3,5)\end{array}$ \\
\hline \multicolumn{3}{|l|}{ 2nd line chemotherapy } \\
\hline FLAG-IDA (fludarabine + cytarabine + idarubicin) & $\begin{array}{l}\text { Fludarabine } \\
\text { Cytarabine } \\
\text { Idarubicin }\end{array}$ & $\begin{array}{l}30 \mathrm{mg} / \mathrm{m}^{2} \text { (days I-5) } \\
2,000 \mathrm{mg} / \mathrm{m}^{2} / \text { day (days I-7) } \\
10 \mathrm{mg} / \mathrm{m}^{2} / \text { day (days I-3) }\end{array}$ \\
\hline MEC (mitoxantrone + etoposide + cytarabine) & $\begin{array}{l}\text { Mitoxantrone } \\
\text { Etoposide } \\
\text { Cytarabine }\end{array}$ & $\begin{array}{l}8 \mathrm{mg} / \mathrm{m}^{2} / \text { day, (days I-6) } \\
80 \mathrm{mg} / \mathrm{m}^{2} / \text { day, (days I-6) } \\
\mathrm{I}, 000 \mathrm{mg} / \mathrm{m}^{2} / \text { day, (days I-6) }\end{array}$ \\
\hline \multicolumn{3}{|l|}{ Other treatments ${ }^{\mathrm{a}}$} \\
\hline $7+3$ (cytarabine + idarubicin $)$ & $\begin{array}{l}\text { Cytarabine } \\
\text { Idarubicin }\end{array}$ & $\begin{array}{l}200 \mathrm{mg} / \mathrm{m}^{2} / \text { day (days I-7) } \\
12 \mathrm{mg} / \mathrm{m}^{2} / \text { day, (days I-3) }\end{array}$ \\
\hline
\end{tabular}

Notes: ancluded in the sensitivity analysis. In the opinion of experts, regimens based on cytarabine and idarubicin are common in Spain as induction therapy, so a sensitivity analysis was also carried out in which the costs of induction treatment with idarubicin and daunorubicin were included.

\section{Analysis}

We used a partitioned survival model with five health states ("diagnosis and induction", "complete remission", "no complete remission", "HSCT" and "death"). The proportion of patients occupying each health state was derived directly from cumulative survival probabilities and was determined by the area under the curves fitted to the RATIFY trial outcomes. The structure of the model is shown in Figure 1.

During the first three years of the model, mortality was estimated from the uncensored overall survival transplant curves in the RATIFY study. ${ }^{6}$ From the fourth year, following the recommendations issued by a panel of clinical experts, mortality was estimated based on the mortality rate of the Spanish general population, ${ }^{12}$ applying an adjustment ( $15 \%$ higher than that of the general population).

\section{Effectiveness}

Effectiveness was measured in life years gained (LYG) and quality-adjusted life years (QALY). LYG were estimated from the overall survival data observed in the RATIFY study. QALYs were estimated by multiplying the time patients spent in each health state by the utility associated with the state and the treatment phase.

Most utilities were obtained from the literature ${ }^{13-17}$ except the utility associated with the state of relapse, which was calculated according to NICE recommendations. ${ }^{9}$ Utilities were validated by a committee of Spanish clinical experts and were represented with a value between 0 and 1 , where 0 represents a state of health similar to death and 1 a state of perfect health. Table 2 shows the utilities included in the model. 


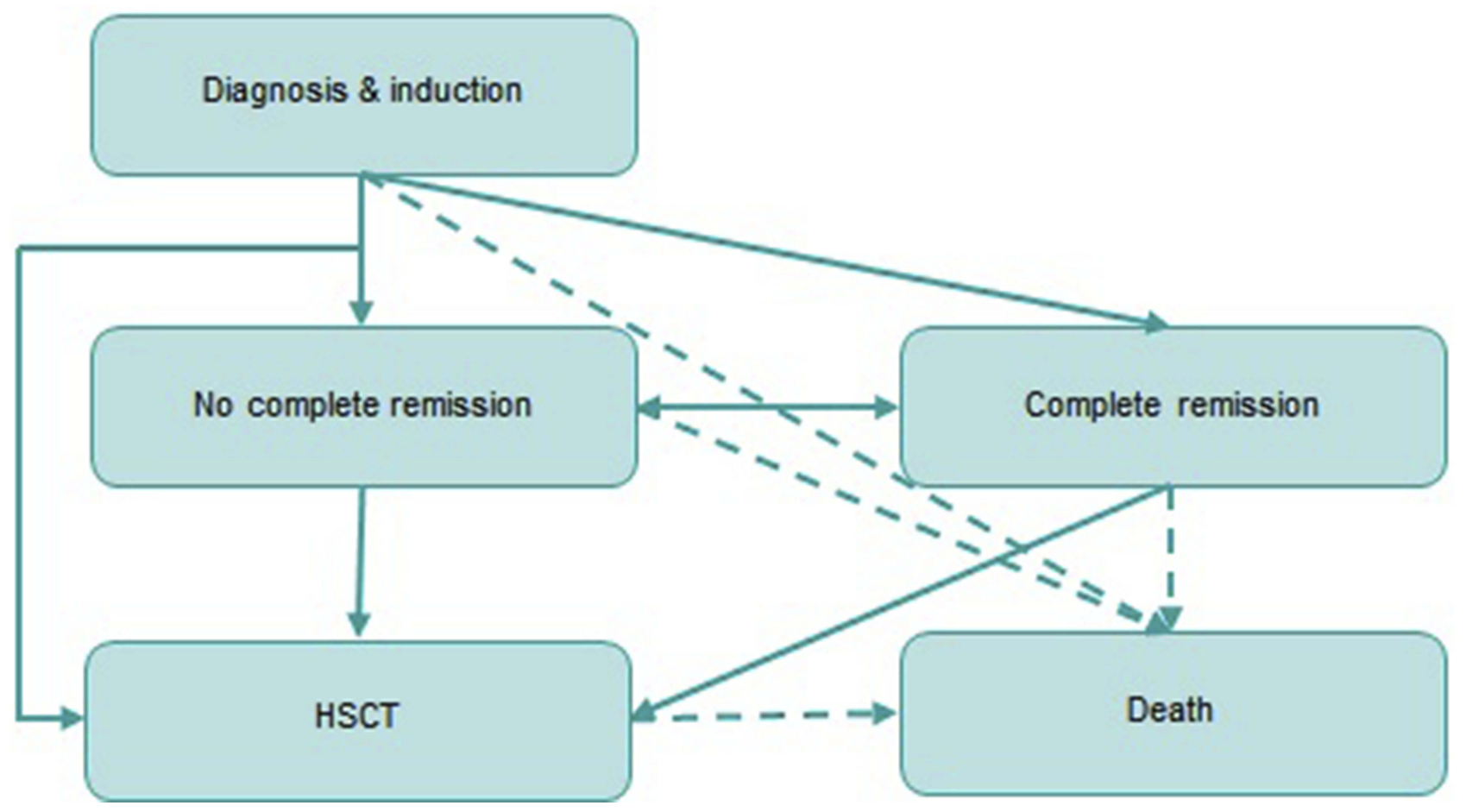

Figure I Model structure.

\section{Use Of Resources And Health Costs}

The costs of first and second line pharmacological therapies and the costs of other health resources (hospitalizations, day

Table 2 Utilities Associated With The Treatment Phases

\begin{tabular}{|c|c|c|}
\hline State & Value & Source \\
\hline Induction ${ }^{\mathrm{a}}$ & 0.648 & Uyl-DE Groot et al, $1998^{13}$ \\
\hline Consolidation $^{\mathrm{a}}$ & 0.710 & Batty et al, $2014^{14}$ \\
\hline Maintenance $^{\mathrm{a}}$ & 0.810 & Batty et al, $2014^{14}$ \\
\hline $\begin{array}{l}\text { CR post Ist line } \\
\text { (no relapse) }\end{array}$ & 0.830 & Leunis et al, $2014^{15}$ \\
\hline Relapse & 0.780 & NICE, $2018^{9}$ \\
\hline $\mathrm{HSCT}^{\mathrm{a}, \mathrm{b}}$ & 0.613 & Crott (2010) \& Grulke $(2012)^{16,17}$ \\
\hline HSCT recovery ${ }^{\mathrm{b}}$ & 0.810 & Crott $(2010) \&$ Grulke $(2012)^{16,17}$ \\
\hline $\begin{array}{l}\text { HSCT follow up } \\
\text { (after Ist line) }\end{array}$ & 0.826 & Crott $(2010) \&$ Grulke $(2012)^{16,17}$ \\
\hline
\end{tabular}

Notes: Includes the disutility associated with treatment. 'Utility values used in the model for SCT treatment, recovery, and post-SCT recovery, were mapped from published (EORTC) Quality of Life Core Questionnaire QLQ-C30 data (Grulke et al 20I2) using an algorithm developed by Crott et al (2010) which calculated EQ-5D utility based on QLQ-C30 scores. The QLQ-C30 data published by Grulke et al presented scores specific to different stages of stem cell therapy (before SCT, during hospitalization, up to 6 months after SCT, and > I year after SCT). The algorithm developed by Crott, et al was then applied to this data in order to obtain EQ-5D utility scores: EQ-5D utility = $0.85927770-0.0069693 *$ (Physical Functioning) $-0.0087346 *$ (Emotional Functioning) $0.0039935 *$ (Social Functioning) $+0.0000355 *$ (Physical Functioning) ${ }^{2}+0.0000552^{*}$

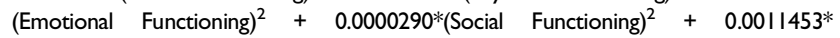
(Constipation) $+0.0039889 *($ Diarrhoea $)+0.0035614 *($ Pain $)-0.0003678 *($ Sleep $)-$ $0.0000540 *(\text { Diarrhoea })^{2}+0.0000117 *(\text { Sleep })^{2}$. hospital visits, emergency room visits, specialist visits, tests) were included. All costs were expressed in 2017 euros.

Costs derived from the management of adverse events were not considered since, in the opinion of the experts, the introduction of midostaurin would not imply any relevant change in the incidence of adverse events, and that most adverse events would occur during induction and consolidation and would thus already be included in the cost of hospital admission. Even during the maintenance phase, the most frequent grade 3 or 4 adverse events (absolute neutrophil count and leukopenia) occurred at similar rates in patients treated with midostaurin or with placebo ${ }^{5}$ thus a similar use of resources at all stages for both treatment arms.

\section{Pharmacological Costs}

The cost of the treatments was estimated from the mean exfactory price (in Spanish "Precio de Venta de Laboratorio" or PVL) of each drug in the database of the General Council of Official Associations of Pharmacists (in Spanish "Consejo General de Colegios Oficiales de Farmacéuticos" or CGCOF $)^{18}$ after applying the discount according to Royal Decree Law (RDL) $8 / 2010^{19}$ (Table 3), and adopting the regimens, doses and timings described in Table 1. 
Table 3 Drug Prices Before And After The Discount According To RDL $8 / 2010^{17}$

\begin{tabular}{|c|c|c|c|}
\hline Drug & PVL & $\begin{array}{l}\text { Discount. } \\
\text { RDL }\end{array}$ & $\begin{array}{l}\text { PVL- } \\
\text { Discount. } \\
\text { RDL }\end{array}$ \\
\hline $\begin{array}{l}\text { Midostaurin }\left(\text { Rydapt }^{\circledR}\right) \\
(25 \mathrm{mg}, 56 \text { capsules })\end{array}$ & $€ 6673.77$ & $4 \%$ & $€ 6406.82$ \\
\hline $\begin{array}{l}\text { Cytarabine gpe } \\
(500 \mathrm{mg}, \text { I vial) }\end{array}$ & $€ 7.19$ & - & $€ 7.19$ \\
\hline $\begin{array}{l}\text { Cytarabine gpe } \\
(\text { I g, I vial) }\end{array}$ & $€ 14.38$ & - & $€ 14.38$ \\
\hline $\begin{array}{l}\text { Cytarabine gpe } \\
(2 \mathrm{~g}, \mathrm{I} \text { vial })\end{array}$ & $€ 28.76$ & - & $€ 28.76$ \\
\hline $\begin{array}{l}\text { Daunoblastin } \\
\text { (daunorubicin) ( } 20 \mathrm{mg}, \mathrm{I} \\
\text { vial) }\end{array}$ & $€ 4.20$ & $15 \%$ & $€ 3.57$ \\
\hline $\begin{array}{l}\text { Fludarabine gpe } \\
(25 \mathrm{mg} / \mathrm{mL}, 2 \mathrm{~mL})\end{array}$ & $€ 49.77$ & - & $€ 49.77$ \\
\hline $\begin{array}{l}\text { Mitoxantrone gpe } \\
\text { (10 mg, I vial) }\end{array}$ & $€ 23.46$ & - & $€ 23.46$ \\
\hline $\begin{array}{l}\text { Etoposide gpe } \\
(20 \mathrm{mg} / \mathrm{mL} \text {, I vial, } 2 \mathrm{~mL})\end{array}$ & $€ 10.06$ & - & $€ 10.06$ \\
\hline $\begin{array}{l}\text { Idarubicin gpe } \\
(\text { ( } 0 \mathrm{mg}, \text { I vial })^{\mathrm{a}}\end{array}$ & $€ 81.80$ & - & $€ 81.80$ \\
\hline
\end{tabular}

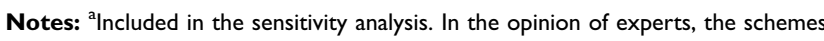
based on the use of cytarabine and idarubicin are also common in Spain induction, so a sensitivity analysis was also carried out in which the costs of the induction treatment with idarubicin and daunorubicin were considered.

Abbreviations: GPE, Generic Pharmaceutical Equivalent; PVL, ex-factory price; RDL, Royal Decree Law.

Following the recommendation of the panel of clinical experts, all calculations were made taking into account the use of complete vials, using the combination of vials that provided the dose closest to the dose required for an average patient with a body surface of $1.7 \mathrm{~m}^{2}$. Table 4 shows the cost per treatment cycle.

\section{Costs Of Non-Pharmacological Health Resources}

During the first three years of stay in the model, the costs of non-pharmacological health resources were estimated from the use of resources in the different treatment states and phases. The use of resources in each health state was defined by a panel of clinical experts and the unit costs of health resources were obtained from the eSalud database $\mathrm{e}^{20}$ (Table 5).

Before starting treatment, it was considered that all patients would undergo a diagnostic test to detect FLT3 mutations.
Table 4 Cost Per Treatment Cycle

\begin{tabular}{|c|c|}
\hline Treatments & Cost/Cycle \\
\hline \multicolumn{2}{|l|}{$I^{\text {st }}$ line chemotherapy: intervention therapy } \\
\hline Induction (cytarabine + daunorubicin + midostaurin) & $€ 6,521.41$ \\
\hline Consolidation (high dose cytarabine + midostaurin) & $€ 6,859.79$ \\
\hline Maintenance (midostaurin) & $€ 12,8 \mid 3.65$ \\
\hline \multicolumn{2}{|l|}{$I^{\text {st }}$ line chemotherapy: Comparator treatment } \\
\hline $7+3$ (cytarabine + daunorubicin $)$ & $€ 114.59$ \\
\hline High dose cytarabine & $€ 452.97$ \\
\hline \multicolumn{2}{|l|}{$2^{\text {nd }}$ line chemotherapy } \\
\hline FLAG-IDA (fludarabine + cytarabine + idarubicin) & $€ \mathrm{I}, 340.8 \mathrm{I}$ \\
\hline MEC (mitoxantrone + etoposide + cytarabine) & $€ 5 \mid 4.44$ \\
\hline \multicolumn{2}{|l|}{ Other treatments ${ }^{a}$} \\
\hline $7+3$ (cytarabine + idarubicin $)$ & $€ 786.53$ \\
\hline
\end{tabular}

Notes: aln the opinion of experts, regimens based on cytarabine and idarubicin are also common in induction therapy in Spain, so a sensitivity analysis was carried out that included the costs of induction therapy with idarubicin and daunorubicin.

Table 5 Unit Costs Of The Health Resources Used In The Analysis

\begin{tabular}{|l|l|}
\hline Resource & Unit Cost \\
\hline Hospitalizations & \\
Hospitalization for chemotherapy (cost/stay) $^{\mathrm{a}}$ & $€ 23,362.91$ \\
Hospitalization for allogeneic HSCT (cost/ $^{\text {process) }}$ & $€ 46,204.70$ \\
Additional hospitalization in a patient with no $^{\mathrm{b}}$ & $€ \mathrm{I}, 146.99$ \\
complete remission (cost/day) $^{\mathrm{c}}$ & \\
Additional hospitalization in a patient in remission $^{\text {(cost/day) }}$ & $€ 1,383.03$ \\
Mortality cost (cost/process) $^{\text {e }}$ & \\
\hline Other health resources $^{\text {FLT-3 test }}$ & $€ 7,635.51$ \\
Day hospital visit $_{\text {Emergency visit }}$ & $€ 327.96$ \\
Specialist visit & $€ 84.32$ \\
Bone marrow aspiration & $€ 177.82$ \\
Complete blood count and biochemistry & $€ 84.32$ \\
\hline
\end{tabular}

Notes: ${ }^{2}$ DRG 205.00: Acute myeloid leukemia with no mention of remission being achieved. ${ }^{b}$ Allogeneic bone marrow transplant (cost/hospitalization). 'Estimated from the cost of the stay equivalent to DRG 205.02 "Acute Myeloid Leukemia in Recurrence" and the length of stay for this DRG stipulated in the CMBD. dEstimated from the cost of the stay equivalent to DRG 205.01 "Acute Myeloid Leukemia in Remission" and the length of stay for this DRG stipulated in the CMBD. ${ }^{e}$ Average cost of hospitalization for a patient with a fatal termination (CMBD). 
Taking into account the opinion of clinical experts, it was considered that all patients would be hospitalized during the induction phase. In the consolidation phase, it was considered that $80 \%$ of patients would be hospitalized to receive the treatment and that the remaining $20 \%$ would receive treatment in a day hospital - with a mean of 8 visits per cycle - and would be admitted for a mean of 5 days for possible complications.

The costs per day of hospitalizations in the "complete remission" and "no complete remission" states were calculated using the mean stay for these admissions included in the 'Conjunto Mínimo Básico de datos' (CMBD) database. ${ }^{21}$ The use of resources used in the states of complete remission and no complete remission are detailed in Table 6.

Finally, it was considered that patients who received an allogeneic HSCT would be hospitalized during the entire transplant process and would make a subsequent follow-up specialist visit in each cycle during the first three years.

According to the NICE recommendations, it was assumed that patients who remained in the model after three years would be considered cured and would not incur additional costs from then onwards. ${ }^{9}$

\section{Sensitivity Analysis}

A univariate deterministic analysis was performed to evaluate the effect of variations in the variables with greater uncertainty. The variables included in this analysis are shown in Table 7.

Discount rates for the costs and benefits of $0 \%$ and $5 \%$, respectively, were applied according to the recommendations of the main national pharmacoeconomic guidelines. ${ }^{7,8}$ Following the recommendations of clinical experts, the effect of substituting daunorubicin for idarubicin for first line therapy was also evaluated.

In addition, according to the NICE recommendations ${ }^{9}$ the following sensitivity analyses were carried out: consider a utility in the state of non-complete remission lower than that considered in the base case (from 0.780 to 0.655 ) to reflect the lower utility of patients receiving a second line of treatment; move the cure point (located in the fourth year of permanence in the model in the base case) to 6.2 years ( 80 cycles) in line with the follow-up period of the RATIFY study; adjust the mortality rate after the fourth year in the model, considering a scenario where the mortality from that year onwards was equal to that of the general population and a scenario where this rate doubled.

Additionally, potential reductions in the PVL of midostaurin $(-20 \%,-30 \%$ and $-40 \%)$, increases in the cost of HSCT (scenarios where the cost of HSCT would be equivalent to the cost of the Diagnosis-Related Group (DRG) associated with allogeneic transplantation and the highest cost of allogeneic HSCT in eSalud, respectively) and a modification of $\pm 20 \%$ in the cost items (pharmacological costs of second line therapy, mortality costs and non-pharmacological health costs during first line treatment) were analyzed.

Finally, a probabilistic sensitivity analysis was carried out by performing 1,000 simulations using the MonteCarlo method; in this analysis, a log-normal distribution was used for the costs, duration of second line therapy,

Table 6 Resource Use In The Complete Remission And No Complete Remission States

\begin{tabular}{|c|c|c|c|c|c|c|}
\hline & & \multicolumn{4}{|c|}{ Complete Remission } & \multirow[t]{2}{*}{ No Complete Remission } \\
\hline & & 0-6 Months & $\begin{array}{l}\text { 6-12 } \\
\text { Months }\end{array}$ & 2-5 Years & $6+$ Years & \\
\hline Specialist visits & $\begin{array}{l}\% \text { patients } \\
\text { Frequency/cycle }\end{array}$ & $\begin{array}{l}100 \% \\
2.0\end{array}$ & $\begin{array}{l}100 \% \\
0.4\end{array}$ & $\begin{array}{l}100 \% \\
0.2\end{array}$ & $\begin{array}{l}100 \% \\
0.1\end{array}$ & $\begin{array}{l}100 \% \\
3\end{array}$ \\
\hline Emergency room visits & $\begin{array}{l}\% \text { patients } \\
\text { Frequency/cycle }\end{array}$ & $\begin{array}{l}60 \% \\
0.25\end{array}$ & $\begin{array}{l}15 \% \\
0.25\end{array}$ & $\begin{array}{l}7.5 \% \\
0.03\end{array}$ & $\begin{array}{l}0 \% \\
0.0\end{array}$ & $\begin{array}{l}62.5 \% \\
1.5\end{array}$ \\
\hline Bone marrow aspiration & $\begin{array}{l}\% \text { patients } \\
\text { Frequency/cycle }\end{array}$ & $\begin{array}{l}100 \% \\
0.2\end{array}$ & $\begin{array}{l}50 \% \\
0.2\end{array}$ & $\begin{array}{l}20 \% \\
0.03\end{array}$ & $\begin{array}{l}0 \% \\
0.0\end{array}$ & $\begin{array}{l}100 \% \\
1\end{array}$ \\
\hline $\begin{array}{l}\text { Complete blood count } \\
\text { and biochemistry }\end{array}$ & $\begin{array}{l}\% \text { patients } \\
\text { Frequency/cycle }\end{array}$ & $\begin{array}{l}100 \% \\
2.0\end{array}$ & $\begin{array}{l}100 \% \\
0.4\end{array}$ & $\begin{array}{l}100 \% \\
0.2\end{array}$ & $\begin{array}{l}0 \% \\
0.0\end{array}$ & $\begin{array}{l}100 \% \\
3\end{array}$ \\
\hline Hospitalizations & $\begin{array}{l}\% \text { patients } \\
\text { Frequency/cycle } \\
\text { Duration (days) }\end{array}$ & $\begin{array}{l}2.5 \% \\
1.0 \\
12.5\end{array}$ & $\begin{array}{l}2.5 \% \\
2.5 \\
12.5\end{array}$ & $\begin{array}{l}2.5 \% \\
0.2 \\
10\end{array}$ & $\begin{array}{l}0 \% \\
0.0 \\
0.0\end{array}$ & $\begin{array}{l}100 \% \\
1 \\
25-30\end{array}$ \\
\hline
\end{tabular}


Table 7 Univariate Deterministic Sensitivity Analysis

\begin{tabular}{|c|c|c|}
\hline Parameter & Base Scenario & Sensitivity Analysis Scenario \\
\hline $\begin{array}{l}\text { Discount on benefits and costs } \\
(0-5 \%)^{a, b}\end{array}$ & $3 \%$ & $0 \% 5 \%$ \\
\hline $\begin{array}{l}\text { Modification of the cost of HSCT } \\
(\text { DRG 803: } € 61,000.07)^{c}\end{array}$ & $€ 46,204.70$ & $€ 61,001.07$ \\
\hline $\begin{array}{l}\text { Modification of the cost of HSCT (highest cost available: } € \\
\text { II } 0,276.59)^{d}\end{array}$ & $€ 46,204.70$ & $€ । 10,276.59$ \\
\hline Utility in the state of complete no remission $(0.655)^{\mathrm{b}}$ & 0.780 & 0.655 \\
\hline Different cure point $(6.2 \text { years })^{\mathrm{b}, \mathrm{e}}$ & 3 years & $\begin{array}{l}6.2 \text { years, derived from the maximum follow-up } \\
\text { of patients in RATIFY }\end{array}$ \\
\hline $\begin{array}{l}\text { Different mortality adjustment after the fourth year }(=/ \times 2 \\
\text { mortality, general population })^{b}\end{array}$ & $\begin{array}{l}15 \% \text { higher than the } \\
\text { general population }\end{array}$ & $\begin{array}{l}\text { Same as the general population. } \\
\text { Twice as high as the general population }\end{array}$ \\
\hline PVL reduction for midostaurin (20-30-40\%) & $100 \%$ & $60 \% 70 \% 80 \%$ \\
\hline Modification of 2 nd line therapy costs $( \pm 20 \%)$ & $100 \%$ & $80 \% 120 \%$ \\
\hline Modification of mortality costs ( $\pm 20 \%)$ & $100 \%$ & $80 \% 120 \%$ \\
\hline Replacement of daunorubicin with idarubicin ${ }^{f}$ & $\begin{array}{l}\text { Daunorubicin } 60 \mathrm{mg} / \mathrm{m} 2 / \text { day } \\
\text { (days } 1-3 \text { ) }\end{array}$ & Idarubicin $12 \mathrm{mg} / \mathrm{m}^{2} /$ day (days I-3) \\
\hline $\begin{array}{l}\text { Modification of non-pharm health costs during Ist line } \\
\text { treatment }( \pm 20 \%)\end{array}$ & $100 \%$ & $80 \% 120 \%$ \\
\hline
\end{tabular}

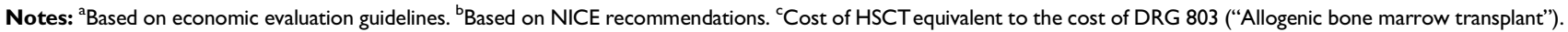

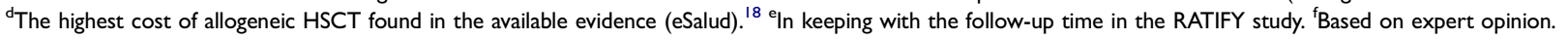

Abbreviation: PVL, ex-factory price.

patients' body surface area and efficacy variables; a gamma distribution for utilities; and beta distributions for pharmacological doses and duration of first line therapy.

\section{Results}

The addition of midostaurin to standard chemotherapy in the treatment of patients with FLT3-AML provided an additional gain in effectiveness over standard chemotherapy. This gain translated into 1.46 LYG and 1.23 QALY gained (Table 8). Outcomes during the first 120 cycles are shown in Figure S1.

Treatment with midostaurin involved an additional cost of $€ 47,955$ versus the comparator. The main cost determinants in the two treatments compared were the costs associated with non-pharmacological health resources, especially hospitalization costs. Although, during treatment, these costs were slightly higher for midostaurin than for the comparator ( $€ 66,568$ vs $€ 60,439$ ), after treatment the hospitalization costs were considerably lower for midostaurin ( $€ 40,230$ vs $€ 60,935$ ), mainly due to a reduction in the costs of relapses versus the comparator ( $€ 21,703$ vs $€ 39,256$ ). This resulted in a total cost of non-pharmacological health resources that was approximately $€ 15,000$ lower for midostaurin versus the comparator (Table 8).

The greatest between-group difference in costs was in the pharmacological costs ( $€ 61,250$ vs $€ 1,798)$, which were higher in the midostaurin group in all treatment phases except for second line therapy. From the total drug costs incurred by the patients in the midostaurin group, $€ 7,973$ were associated to the induction phase, $€ 12,881$ to consolidation and $€ 39,870$ to the maintenance treatment while $€ 527$ were second line therapy costs (Table 8).

The reductions in costs associated with mortality ( $€ 5,082$ vs $€ 5,413$ ), together with the reductions in the costs of non-pharmacological health resources, partially offset the increases in pharmacological costs and in the costs associated with HSCT in patients treated with midostaurin (Table 8 ). In the base case, the incre- 
Table 8 Results Of The Cost-Effectiveness And Cost-Utility Analyses. Base Case

\begin{tabular}{|c|c|c|c|}
\hline & Midostaurin + Chemotherapy & Chemotherapy & Incremental \\
\hline \multicolumn{4}{|l|}{ Cost } \\
\hline Pharmacological cost & $€ 61,250$ & $€ \mathrm{I}, 798$ & $€ \mathbf{5 9 , 4 5 2}$ \\
\hline Induction & $€ 7,973$ & $€ 466$ & $€ 7,507$ \\
\hline Consolidation & $€|2,88|$ & $€ 744$ & $€ 12,138$ \\
\hline Maintenance & $€ 39,870$ & $€ 0$ & $€ 39,870$ \\
\hline 2nd line therapy & $€ 527$ & $€ 589$ & $€-62$ \\
\hline $\begin{array}{l}\text { Cost of healthcare resources } \\
\text { (non-pharmacological) }\end{array}$ & $€ 106,798$ & $€|2|, 374$ & $€-14,576$ \\
\hline During treatment & $€ 66,568$ & $€ 60,439$ & $€ 6,129$ \\
\hline After treatment & $€ 40,230$ & $€ 60,935$ & $€-20,705$ \\
\hline HSCT costs & $€ \mathbf{3 4 , 7 2 3}$ & $€ 31,315$ & $€ 3,409$ \\
\hline Costs of mortality & $€ 5,082$ & $€ 5,413$ & $€-331$ \\
\hline TOTAL COST & $€ 207,854$ & $€ 159,900$ & $€ 47,955$ \\
\hline \multicolumn{4}{|l|}{ Effectiveness } \\
\hline LYG & 11.73 & 10.27 & 1.46 \\
\hline QALYs & 9.45 & 8.22 & 1.23 \\
\hline ICER (€ per LYG): & \multicolumn{3}{|l|}{$€ 32,854$} \\
\hline ICUR (€ per QALY gained): & \multicolumn{3}{|l|}{$€ 38,985$} \\
\hline
\end{tabular}

Note: The values that are not in bold are components of the items in bold.

Abbreviations: QALY, Quality Adjusted Life Year; LYG, Life year gained; ICER, Incremental Cost Effectiveness Ratio; ICUR, Incremental Cost Utility Ratio.

mental cost-utility ratio (ICUR) for midostaurin and chemotherapy treatment was $€ 38,985 /$ QALY.

The univariate sensitivity analysis (Figure 2) showed that the results of the model are robust. In addition, the application of potential discounts to the PVL of midostaurin produced cost-effectiveness results below $€ 30,000$ / QALY; a $20 \%$ discount in the PVL of midostaurin translated the RCUI into $€ 29,326 /$ QALY, while RCUIs of $€ 24,496 /$ QALY and $€ 19,666 /$ QALY were obtained under discounts of $30 \%$ and $40 \%$, respectively. The results of the probabilistic sensitivity analysis show that, when the efficiency threshold was set at $€ 50,000$ /QALY, treatment with midostaurin was a cost-effective option in $82.3 \%$ of the simulations (Figure 3).

\section{Discussion}

Currently, induction and consolidation therapy followed by allogeneic HSCT constitute the basis of the management of intermediate or high risk FLT3-AML. Although this treatment is intended to cure, the prognosis of the disease remains poor, especially in patients refractory to primary treatment and in those who, despite meeting eligibility criteria to receive an allogeneic HSCT, cannot receive it or cannot receive it in optimal conditions as they have not achieved CR after first line therapy. ${ }^{22}$ Improving clinical outcomes in first line therapy is an unmet medical need in the management of FLT3-AML.

Midostaurin is the first targeted treatment which, in combination with standard induction and consolidation chemotherapy and as maintenance therapy after induction and consolidation, has shown benefits in the survival of patients with newly-diagnosed FLT3-AML. ${ }^{6}$ Our results show that the addition of midostaurin to standard chemotherapy based on cytarabine and daunorubicin, followed by maintenance treatment with midostaurin, could be a cost-effective intervention in Spain.

In the base case, it was estimated that the introduction of midostaurin would produce gains of 1.46 LYG, 1.23 QALYs and an additional cost of $€ 47,955$, resulting in an incremental cost-effectiveness ratio (ICER) of $€ 32,854 / \mathrm{LYG}$ and an ICUR of $€ 38,985 /$ QALY. These results are similar to those observed in the economic evaluations of midostaurin in Canada and the United Kingdom, in which ICURs of $\$ 66,937$ and $£ 34,327$ were observed, respectively. ${ }^{23,24}$ 


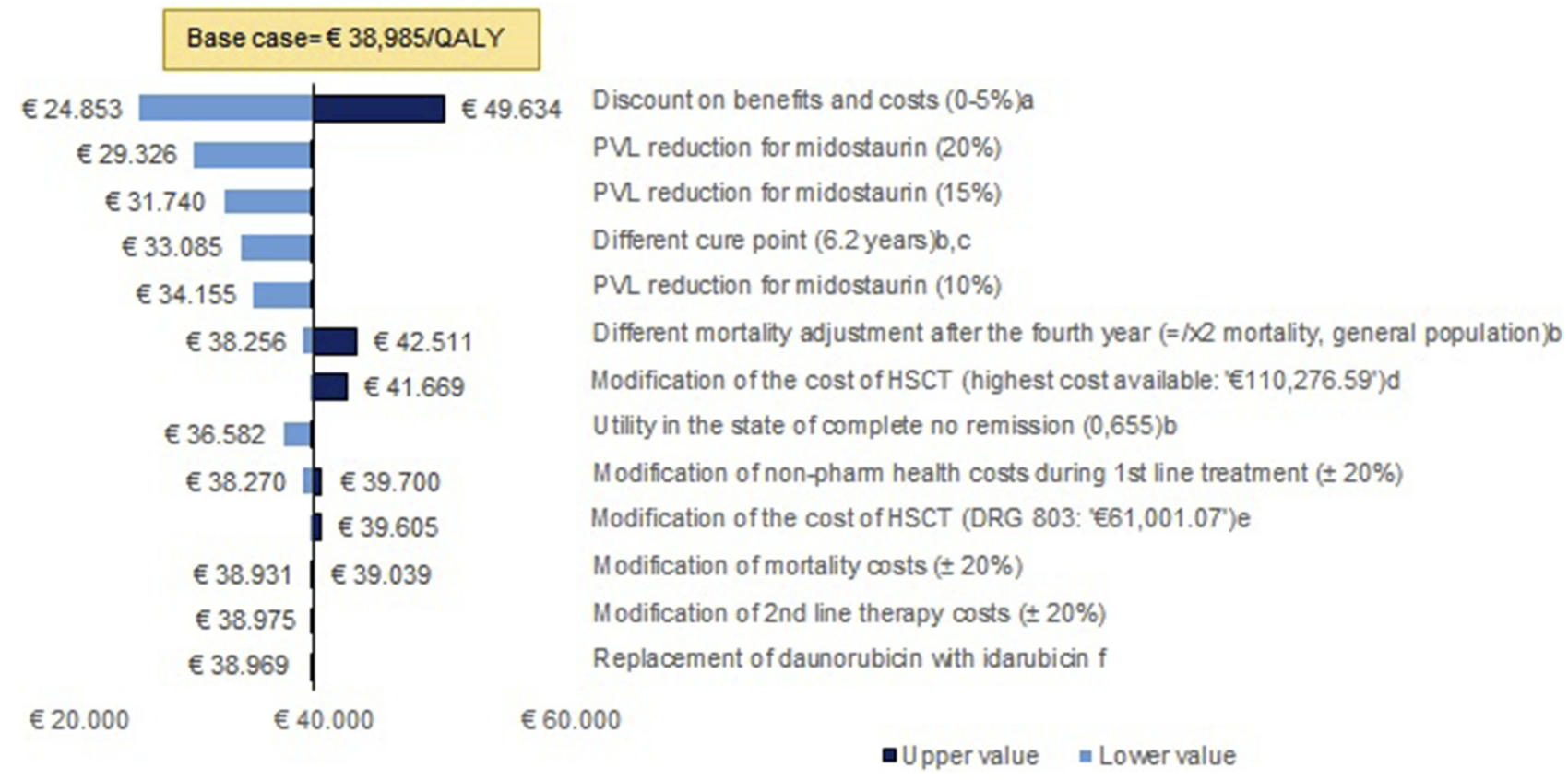

Figure 2 Univariate sensitivity analysis. a. Based on economic evaluation guidelines. b. Based on NICE recommendations. c. In keeping with the follow-up time in the RATIFY study. d. The highest cost of allogeneic HSCT found in the available evidence (eSalud). e. Cost of HSCT equivalent to the cost of DRG 803 ("Allogenic bone marrow transplantation"). f. Based on expert opinion.

Abbreviations: $A E$, adverse events; PVL, ex-factory price.

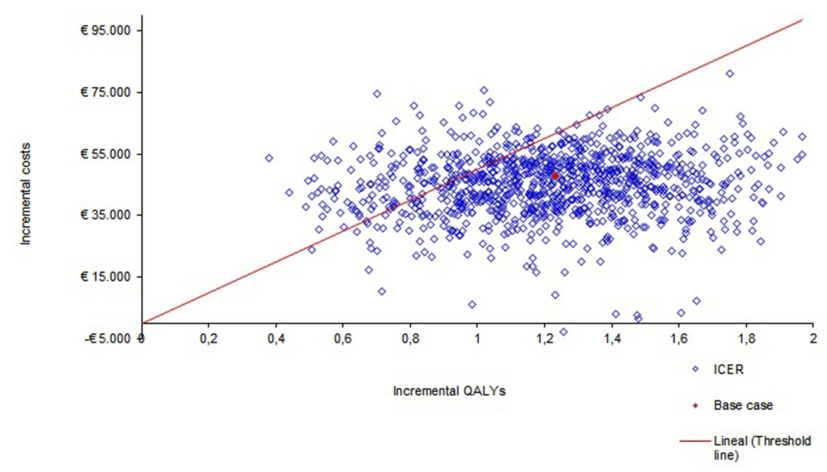

Figure 3 Probabilistic sensitivity analysis.

Both the ICER and the ICUR are below the thresholds used in orphan diseases in Spain, ${ }^{2}$ which may exceed $€ 100,000 / \mathrm{QALY},{ }^{25,26}$ and below the efficiency thresholds stipulated by the World Health Organization (WHO), which is up to three times the gross domestic product per capita in Spain $(77,400 € / \mathrm{QALY}){ }^{27}$

The deterministic and probabilistic sensitivity analyses demonstrate the robustness of the results. In the deterministic analysis, when a discount between $20 \%$ and $40 \%$ was applied to the price of midostaurin and discounts on benefits and costs were not taken into account, the ICUR was below a threshold of $€ 30,000 /$ QALY, which is a commonly accepted threshold in Spain. ${ }^{28}$
In addition, taking into account the potential of midostaurin to increase the proportion of patients who are transplanted, the robustness of the results with respect to the variations in the cost of HSCT is also especially relevant. When the costs of the intervention were doubled (using a unit cost of $>€ 110,000$ ), the results would still remain below $€ 42,000 / \mathrm{QALY}$.

In the probabilistic analysis, treatment would continue to be a cost-effective intervention in $82.3 \%$ of the simulations if a threshold of $€ 50,000 /$ QALY was considered (Figure 3).

Given the lack of published evidence, it is difficult to compare the efficiency of midostaurin with that of interventions used in the management of other hematologic neoplasms in Spain.

Our results also show that using midostaurin in combination with standard induction and consolidation chemotherapy would help to improve the efficiency of these processes, which are very expensive due to the high costs incurred by hospitalizations for treatment. The results also show that increases in pharmacological costs due to the introduction of midostaurin would be partially compensated by cost reductions in the management of relapses, and especially by reductions in hospitalizations to receive second line therapy. 
Although a front-line allogeneic HSCT is generally recommended in FLT3-AML patients, especially in those with higher risk disease, a large proportion of patients cannot finally be transplanted because there is no compatible donor or for other reasons. In the RATIFY study, both transplant and non-transplant patients benefited from the introduction of midostaurin. Therefore, maintenance treatment with midostaurin, in addition to promoting CR and possible HSCT in $\mathrm{CR}$, would be a treatment option in patients who have $\mathrm{CR}$ after induction and consolidation and have an indication for allogeneic HSCT but cannot receive it, as well as for those with low-intermediate risk of relapse.

As it is an orally-administered treatment with a good safety and tolerability profile, the costs of maintenance treatment with midostaurin are limited to the pharmacological costs. Taking into account the treatment times observed in the RATIFY study, it may be estimated that, in an average patient, the cost of complete treatment with midostaurin would be around $€ 60,000$, of which $€ 40,000$ would correspond to the maintenance phase. In any case, it is worth noting that, while this study has considered the midostaurin treatment costs for all the phases included in the RATIFY study and approved by the EMA (induction, consolidation and maintenance), the maintenance phase is not currently reimbursed in Spain. Therefore, in clinical practice, patients would only incur the pharmacological costs of induction and consolidation. Further research is needed to determine the cost-effectiveness of midostaurin when the maintenance phase is omitted.

When comparing two potentially curative interventions, and in line with the recommendations of pharmacoeconomic guidelines, our study adopted a lifetime time horizon. The availability of long-term overall survival and disease-free survival results from the RATIFY study shows that the curves reached a plateau approximately three years after study initiation, confirming that patients who remained alive would be virtually cured. In addition, when the cure point was delayed to 6.2 years (maximum follow-up of the RATIFY study), the ICUR results are even more favorable than in the base case ( $€ 33,085$ / QALY), which suggests that the establishment of a cure point at three years is a conservative assumption for midostaurin with respect to the comparator and that the efficiency of midostaurin could extend beyond the maximum follow-up time observed in the clinical trial.

This study incorporated the main NICE recommendations based on the authorization process of midostaurin in the United Kingdom. This reinforces the validity and reliability of the model and its alignment with the requirements of one of the main European health technology agencies. However, the study has some limitations. One limitation is that only the direct costs of the disease and its treatment were analyzed, since the associated indirect costs should be taken into account in patients with FLT3-AML, especially those who relapse or receive HSCT. Although, according to economic evaluation guidelines, the social perspective is the most appropriate, ${ }^{7}$ the perspective most commonly used in GENESIS reports ${ }^{8}$ and in the cost-effectiveness analyses published for other drugs indicated for hematologic neoplasms in Spain ${ }^{29,30}$ is that of the Spanish National Health System. Another limitation is the lack of quality of life results in patients treated with midostaurin or the comparator, which forced us to use utility values collected from the literature. However, in a sensitivity analysis in which the utility associated with relapse was reduced, the results of the ICUR were more favorable than those observed in the base case. Finally, our analysis considered that the toxicity profile of midostaurin was similar to that of the comparator. Therefore, data on adverse events were not included. However, NICE considered it important to take into account the adverse events derived from HSCT, given that certain events, such as graft-versus-host disease, could have a significant impact on the results. Further research on this area is needed to ascertain the economic implications of HSCT-related adverse events.

\section{Conclusions}

This study shows that midostaurin, in combination with standard chemotherapy, is emerging as an efficient alternative for the treatment of recently-diagnosed FLT3-AML in Spain. According to our modeling, the introduction of midostaurin could reduce the costs associated with disease relapse and improve both life expectancy and quality of life of Spanish patients with FLT3-AML.

\section{Abbreviations}

AE, adverse event; AML, acute myeloid leukemia; CADTH, Canadian Agency for Drugs and Technologies in Health; CGCOF, Consejo General de Colegios Oficiales de Farmacéuticos; CI, confidence interval; CMBD, Conjunto Mínimo Básico de Datos; CMV, cytomegalovirus; $\mathrm{CR}$, complete remission; DRG, diagnosis-related group; FLAG-IDA, fludarabine, cytarabine, idarubicin; FLT3, FMS-like tyrosine kinase 3; GPE, generic pharmaceutical equivalent; GVHD, graft versus host disease; HAS, Haute Autorité de Santé; HR, hazard ratio; HSCT, 
hematopoietic stem cell transplantation; ICER, incremental cost-effectiveness ratio; ICU, intensive care unit; ICUR, incremental cost-utility ratio; LYG, life year gained; MEC, mitoxantrone, etoposide, cytarabine; NICE, National Institute for Health and Care Excellence; PVL, ex-factory price; QALY, quality-adjusted life year; RDL, royal decree law; VZV, varicella-zoster virus; WHO, World Health Organization.

\section{Acknowledgments}

The authors of the manuscript wish to thank Dr. Elena Amutio for his participation in the panel of experts who validated the model inputs and assumptions, and Gabriel Tremblay for his support during the performance of the sensitivity analyses.

\section{Author Contributions}

Each author of the present work affirms that:

- They have participated substantially in the work (conception and design of the study, or acquisition, analysis, and interpretation of data) taking public responsibility for the content of the paper and has critically revised and approved the final version of the manuscript.

- Agree to be accountable for all aspects of the study, ensuring that questions related to the accuracy or integrity of any part of the study are appropriately investigated and resolved.

- If requested, the authors will provide the data or will cooperate fully in obtaining and providing the data on which the manuscript is based for examination by the editors or their assignees.

\section{Disclosure}

AA, RD, JE, CM, JS and JLV are, respectively, employed by San Carlos Hospital, University Hospital of Getafe, Clinic Hospital of Barcelona, University Hospital of Araba, Hospital Santa Creu i Sant Pau and Hospital Sant Joan de Déu. JS reports grants and personal fees from Novartis and personal fees from Daiichi Sankyo, during the conduct of the study and grants and personal fees from Novartis, outside the submitted work. CM reports nonfinancial support from Novartis, outside the submitted work. JML is employed by Hospital 12 de Octubre, CNIO and Complutense University and reports grants and personal fees from Novartis, Janssen, Bms, and Incyte, during the conduct of the study. PM is employed by University Hospital La Fe and CIBERONC - Instituto
Carlos III. DML and AMF are employees of Oblikue Consulting, an independent contract health economic organization that received consultancy fees from Novartis Farmacéutica, S.A. to conduct this research. AMF reports grants from Oblikue Consulting, during the conduct of the study. RDN and JG are employees of Novartis Farmacéutica, S.A., the marketing authorization holder for Rydapt ${ }^{\circledR}$ (midostaurin). The funding body was not involved in the study design, collection and interpretation of the data, or the decision to publish. The authors report no other conflicts of interest in this work.

\section{References}

1. O'Donnell MR, Tallman MS, Abboud CN, et al. Acute myeloid leukemia, version 3.2017, NCCN clinical practice guidelines in oncology. J Natl Compr Cancer Netw. 2017;15(7):926-957. doi:10.6004/jncen.2017.0116

2. Infante MS, MÁ P, Hernández-Rivas JÁ. Alteraciones moleculares en leucemia mieloide aguda y sus implicaciones clínicas y terapéuticas [Molecular alterations in acute myeloid leukemia and their clinical and therapeutical implications]. Med Clin (Barc). 2018. doi:10.1016/ j.medcli.2018.05.002

3. Fey MF, Buske C; Group on behalf of the EGW. Acute myeloblastic leukaemias in adult patients: ESMO clinical practice guidelines for diagnosis, treatment and follow-up. Ann Oncol. 2013;24(suppl_6): vi138-vi143. doi:10.1093/annonc/mdt320

4. Döhner H, Estey E, Grimwade D, et al. Diagnosis and management of AML in adults: 2017 ELN recommendations from an international expert panel. Blood. 2017;129(4):424-447. doi:10.1182/blood-201608-733196

5. European Medicines Agency (EMA). Midostaurin. Summary of Product Characteristics. Rydapt $25 \mathrm{mg}$ Soft Capsules. Available from: https://www.ema.europa.eu/en/documents/product-informa tion/rydapt-epar-product-information_en.pdf. Accessed August 6, 2019.

6. Stone RM, Mandrekar SJ, Sanford BL, et al. Midostaurin plus chemotherapy for acute myeloid leukemia with a FLT3 mutation. $N$ Engl $J$ Med. 2017;377(5):454-464. doi:10.1056/NEJMoa1614359

7. López Bastida J, Oliva J, Antoñanzas F, et al. Propuesta de guía para la evaluación económica aplicada a las tecnologías sanitarias. Gac Sanit. 2010;24:154-170. doi:10.1016/j.gaceta.2009.07.011

8. Ortega Eslava A, Marín Gil R, Fraga Fuentes MD, López-Briz E, Puigventós Latorre F. Guía De Evaluación Económica E Impacto Presupuestario En Los Informes De Evaluación De Medicamentos. Guia Práctica Asociada Al Programa MADRE V 4.0. Madrid: SEFH ; 2016. ISBN: 978-84-617-6757-1

9. National Institute of Health and Care Excellence. Midostaurin for Untreated Acute Myeloid Leukaemia. 2018. Available from: https:// www.nice.org.uk/guidance/ta523. Accessed August 6, 2019.

10. Pan-Canadian Oncology Drug Review Final Economic Guidance Report Midostaurin (Rydapt) for Acute Myeloid Leukemia; 2017. Available from: www.cadth.ca/pcodr. Accessed August 6, 2019.

11. Haute Autorité de Santé. Available from: https://www.has-sante.fr/ upload/docs/application/pdf/2018-10/rydapt-lam_22052018_avis_ efficience.pdf. Accessed August 6, 2019.

12. Insituto Nacional de Estadística. Mortalidad por sexo y edad. 2018.

13. Uyl-de Groot CA, Lowenberg B, Vellenga E, Suciu S, Willemze R, Rutten FF. Cost-effectiveness and quality-of-life assessment of GM$\mathrm{CSF}$ as an adjunct to intensive remission induction chemotherapy in elderly patients with acute myeloid leukemia. $\mathrm{Br} J$ Haematol. 1998;100(4):629-636. doi:10.1046/j.1365-2141.1998.00635.x 
14. Batty N, Yin Y, Wetzler M. Decitabine is more cost effective than cytarabine and daunorubicin in elderly acute myeloid leukemia patients. J Cancer Res Ther. 2014;2(4):68-73. doi:10.14312/20524994.2014-9

15. Leunis A, Redekop WK, Uyl-de Groot CA, Löwenberg B. Impaired health-related quality of life in acute myeloid leukemia survivors: a single-center study. Eur J Haematol. 2014;93(3):198-206. doi:10.1111/ejh.12324

16. Crott R, Briggs A. Mapping the QLQ-C30 quality of life cancer questionnaire to EQ-5D patient preferences. Eur J Heal Econ. 2010;11(4):427-434. doi:10.1007/s10198-010-0233-7

17. Grulke N, Albani C, Bailer H. Quality of life in patients before and after haematopoietic stem cell transplantation measured with the European Organization for Research and Treatment of Cancer (EORTC) Quality of Life Core Questionnaire QLQ-C30. Bone Marrow Transplant. 2011;47:473. doi:10.1038/bmt.2011.107

18. Consejo General de Colegios Oficiales de Farmacéuticos (CGCOF). Consejo General de Colegios Oficiales de Farmacéuticos. Base de datos del conocimiento sanitario. 2016.

19. Ministerio de Sanidad Consumo y Bienestar Social (MSCBS). Real Decreto-Ley 8/2010 De 20 De Mayo, Por El Que Se Adoptan Medidas Extraordinarias Para La Reducción Del Déficit Público. Boletín Oficial del Estado. 2010.

20. Gisbert R, Brosa M Base de datos de costes sanitarios y ratios costeefectividad españoles: eSalud [Internet]. Available from: http://esa lud.oblikue.com/. Accessed November 2017.

21. Ministerio de Sanidad Servicios Sociales e Igualdad (MSSSI). Conjunto Mínimo Básico de Datos (CMBD).

22. Rashidi A, Weisdorf DJ, Bejanyan N. Treatment of relapsed/refractory acute myeloid leukaemia in adults. Br J Haematol. 2018;181 (1):27-37. doi:10.1111/bjh.15077

23. Tremblay G, Dolph M, El Ouagari K, Brandt P, Forsythe A. CostEffectiveness Analysis of Midostaurin (MIDO) With Standard of Care (SOC) for Acute Myeloid Leukemia (AML) in Canada. Value Heal. 2018;21:S28-S29. doi:10.1016/j.jval.2018.04.180
24. Tremblay G, Dolph M, Patel S, Brandt P, Forsythe A. Cost-effectiveness analysis of midostaurin (MIDO) with Standard Chemotherapy (SOC) for Acute Myeloid Leukemia (AML) in the United Kingdom (UK). Value Heal. 2017;20(9):A399. doi:10.1016/ j.jval.2017.08.005

25. Brosa M, García Del Muro X, Mora J, et al. Orphan drugs revisited: cost-effectiveness analysis of the addition of mifamurtide to the conventional treatment of osteosarcoma. Expert Rev Pharmacoecon Outcomes Res. 2015;15(2):331-340. doi:10.1586/14737167.2 015.972378

26. Núñez M, Gil B, Sacristán JA, Dilla T. Analysis of orphan drugs marketed in spain during the period 2010-2015: epidemiological, clinical and economic characteristics. Health Econ Outcome Res Open Access. 2017;3:140. doi:10.4172/2471-268X.1000140

27. Robinson LA, Hammitt JK, Chang AY, Resch S. Understanding and improving the one and three times GDP per capita cost-effectiveness thresholds. Health Policy Plan. 2017;32(1):141-145. doi:10.1093/ heapol/czw096

28. Sacristán JA, Oliva J, Del LJ, Prieto L, Pinto JL. ¿Qué es una tecnología sanitaria eficiente en España? Gac Sanit. 2002;16 (4):334-343. doi:10.1016/S0213-9111(02)71933-X

29. Crespo C, Moreno E, Sierra J, Serip S, Rubio M. Cost-effectiveness analysis of azacitidine in the treatment of high-risk myelodysplastic syndromes in Spain. Health Econ Rev. 2013;3:28. doi:10.1186/21911991-3-28

30. Casado LF, Hernández JÁ, Jarque I, Echave M, Casado MA, Castro A. Cost-utility analysis of idelalisib in combination with rituximab in relapsed or refractory chronic lymphocytic leukaemia. Eur J Haematol. 2017;100(3):264-272. doi:10.1111/ejh.13007
ClinicoEconomics and Outcomes Research

\section{Publish your work in this journal}

ClinicoEconomics and Outcomes Research is an international, peerreviewed open-access journal focusing on Health Technology Assessment, Pharmacoeconomics and Outcomes Research in the areas of diagnosis, medical devices, and clinical, surgical and pharmacological intervention. The economic impact of health policy and health systems

\section{Dovepress}

organization also constitute important areas of coverage. The manuscript management system is completely online and includes a very quick and fair peer-review system, which is all easy to use. Visit http://www.dovepress.com/testimonials.php to read real quotes from published authors.

Submit your manuscript here: https://www.dovepress.com/clinicoeconomics-and-outcomes-research-journal 